\title{
Analysis of Digital Marketing of China's Automobile Manufacturing Industry During Pandemic Time
}

\begin{abstract}
Yixuan Lin*
Department of Management, University College Dublin Belfield, Dublin 4, Ireland.

${ }^{*}$ Corresponding author. Email: yixuanl0213@163.com

ABSTRACT

The COVID-19 outbreak has had a great impact on many companies, and the economic losses caused by the inability to resume work in the short term are also immeasurable. Some companies have used some online communication software such as DingTalk to solve their communication problems. Enterprises not only need to solve communication problems, but also solve online and offline collaboration problems. The prerequisite for people to achieve "non-contact" production is to solve the coordination of people, people and machines, machines and machines, and the upstream and downstream of the industrial chain. This article examines how the car sector has adapted to the digital marketing transformation in the aftermath of the epidemic. The research methods of this report is through various literature reviews. This study found that under the influence of digital development, the automobile manufacturing industry can discover new innovations during the epidemic, from $\mathrm{R} \& \mathrm{D}$ and manufacturing to terminal marketing and even after-sales service.
\end{abstract}

Keywords: Covid-19, digital marketing transformation, automobile manufacturing industry, online collaboration.

\section{INTRODUCTION}

The rapid onset of the COVID-19 outbreak has exacerbated China's auto industry's problems. According to the China Automobile Association, national passenger car sales decreased by more than $80 \%$ year on year in February 2020[4]. According to McKinsey, a global management consulting company, affected by the epidemic, global car sales will drop by $27 \%$ in 2020 , and sales in China will drop by $14 \%$. It is not expected to rebound in the near future. Under strict prevention and control of the epidemic, the economic order in most parts of the country has gradually improved. More and more companies have switched from fighting the epidemic to returning to work after the epidemic. After the outbreak, the auto market and industrial structure would alter as well. The problem is that the disease has suppressed demand for vehicles purchases[4]. Domestic auto supply is projected to be insufficient in the coming months, putting pressure on automakers' output and sales. It is possible that consumer demand for automobiles will be delayed. This article will study the transformation of automakers' digital marketing strategies under the influence of the pandemic in China. The author will use literature analysis to discuss the digital transformation strategies adopted by large manufacturers and the trends in the automotive industry.

\section{ANALYSIS OF MARKETING ENVIRONMENT OF CAR MANUFACTURING INDUSTRY}

\subsection{External Analysis of Car Manufacturing industry in China}

\subsubsection{PEST model theory}

PEST is for Political, Economy, Society, and Technology, and is mostly used for industry analysis.It refers to the understanding of the current situation and changing laws of the macro-environment from the four aspects of politics, economy, society and technology. As each industry and enterprise has different characteristics and business needs, the specific content of the analysis will be different, but all four types of influencing factors, including politics, economy, technology, and society, should be examined. 


\subsection{Automotive market PEST analysis}

\subsubsection{P-political environment}

As one of the pillar industries of GDP, the automobile industry needs to shoulder the important task of stabilizing economic development. In May 2020, 11 departments including the National Development and Reform Commission and the Ministry of Information Technology jointly issued the "Measures for Stabilizing the Expansion of Automobile Consumption." This measure includes the adjustment and implementation of National VI emission standards, and the improvement of fiscal and taxation support related to automobile consumption [9]. Policies are aimed at different market segments, and pollution regulations for fuel vehicles are becoming stricter. On the contrary, charging piles, subsidies and purchase taxes will be widely implemented. With the extension of the policy period, the new energy vehicle market will undoubtedly usher in rapid growth.

\subsubsection{E-economic environment}

Since 2018, macroeconomic deleveraging has put a strain on corporate operations and influenced people' income expectations, limiting the purchasing of large-ticket items [9]. In contrast, housing prices have risen too fast in the past two years, especially in some developing cities Multiple panic and speculative housing demand stifled automotive consumption, resulting in a significant debt burden and a significant decrease in household and automotive consumption. The rate of macroeconomic growth is slowing. National per capita income continues to rise, but people' $\mathrm{s}$ propensity to consume cars may generally decline. Luxury car sales may continue to climb against the market as a result of the national "consumption upgrading" trend.

\subsubsection{S-social situation}

Urban traffic congestion and pollution have become more prominent in recent years. As people's awareness of environmental protection and low-carbon travel is gradually increasing, car sharing is becoming more and more popular, and the willingness of young people to buy cars may be weakened[9]. The public's demand for private travel space and unfettered movement capabilities may lead to the purchase of automobiles.

\subsubsection{T-Technology Environment}

The "new four modernizations," namely electrification, intelligence, networking, and sharing, are the primary technical development trends of the future car. In 2015, the industry formally presented the concept of "New Four Modernizations." Along with automakers, more and more Internet businesses (such as Baidu and Ali) and $3 \mathrm{C}$ businesses (such as Huawei) have gradually grown their exposure to driverless driving, in-vehicle entertainment systems, and smart cockpits during the last five years. Automotive product technology and quality will become the most crucial core competitiveness of automakers in the future.The PEST study has given an in-depth explanation of the vehicle market. The four factors of politics, economy, society, and technology can all influence the industry. China is a country with potential rising demand for automobiles, and the car manufacturing industry in China has been receiving strong support from the government.

\section{MARKETING DIGITALIZATION DEVELOPMENT IN AUTOMOTIVE INDUSTRY DURING PANDEMIC}

Digitalization has begun to play a very crucial synergy in the supply chain system; on the marketing side, the role of digital marketing has also begun to rise. As a digital marketing technology supplier, adding effective expertise in car agency systems and marketing may provide some insights for car companies. If an automotive firm wants to achieve digital marketing, it must open up both the supply and demand sides' major data systems and create a full-staff promotion platform. This type of partnership between individuals, businesses, and businesses has existed since the dawn of entrepreneurship. Those automakers who already have a digital strategy in place will be in the lead throughout this epidemic.

BMW China's CMO noted that the company has been working as a digital promotion center that unifies all workers and a system for agencies. It is currently available on the internet and has uses in shopping malls[1]. The current data center has established automatic marketing content. Through open data and business systems, marketing has become an automatic marketing method. In order to carry out online marketing, many car companies are actively opening up customers' internet links such as car viewing, test drive, car selection, and car purchase by customers. Consumers are increasingly turning to online $4 \mathrm{~S}$ stores to keep up with the latest models. Especially in places with severe epidemics, consumers are more willing to choose online car purchase methods and door-to-door service technologies. As a result, Jiatui CEO Peng Chao feels that in the past, buyers' car viewing and test driving were all done offline during auto sales [9]. This epidemic forced automobile firms to adopt augmented reality and virtual reality (AR/VR) technology to allow buyers to see the interior of the vehicle and simulate test rides. Automobile is a huge and high-value product. Compared with $3 \mathrm{C}$ products, it emphasizes more on experience and requires a better online experience. Therefore, many automakers are experimenting with 
augmented reality and virtual reality to make car shopping and driving more immersive. During this epidemic, it is expected that some emergency digital application support technologies will become commonplace in the organization and gradually solidify into a part of the new digital enterprise.

\section{NEW TRENDS IN AUTOMOBILE INDUSTRY'S DIGITAL MARKETING}

Under the influence of digital development, the automobile manufacturing industry is expected to seek various breakthrough points during the epidemic, ranging from $R \& D$ and manufacturing to end marketing and even after-sales service. There were three key themes in the automotive manufacturing industry's digital marketing throughout the epidemic.

\subsection{Trend 1: User-centric digital marketing system}

The most significant shift for people throughout the epidemic is that they have grown accustomed to connecting brands and service providers through the internet [9]. Users are getting better and better services online as businesses and service providers improve their services. Automobile firms' attempts to transition from offline to front line, in reality, many car firms have made numerous attempts prior to the epidemic.Obviously, the epidemic has forced business departments to connect users, distributors, and products through digitalization. Through the rapid development of digital experience platforms, a user-centric digital marketing system for car viewing and car purchase has gradually formed. [5].

Users can conduct business that previously required them to visit $4 \mathrm{~S}$ stores without ever leaving their homes. This is prompting OEMs to create a business center and promotion hub prototype, as well as connect users and offline retailers via these platforms in order to deliver more information [9]. Good users keep an eye on cars, buy cars, services, and open all the businesses in the sales chain.

The demand for digital marketing is different before and after the epidemic. From the user's point of view, it is more about the user's digital experience before the epidemic. After the epidemic, services should be customized around user experience.The urgency of digital exploration has increased as a result of this epidemic.

\subsection{Trend 2. All products are services, and all services are content, which is then converted into traffic, which is then converted into sales.}

Well-designed product promotion content can increase sales. Companies must differentiate themselves in content marketing if they want to win favor with customers, maintain stickiness, and create new business value. For example, BMW has developed an online digital content platform that covers the entire life cycle of users. This platform integrates and links various media resources and online hot information, and imports various marketing materials from car companies to provide dealers with diversified marketing content materials. These content materials are adapted by the seller and then output in the form of articles, picture posters, H5, short videos, etc.[6]. Every BMW document may be readily changed to include content such as items or forms, and to enable the content creation of targeted marketing for dealers.

\subsection{Trend 3: Exploring the business value of data and promoting corporate development}

In order to promote the development of the sales field, auto companies need to pay more attention to the integration of users, ecology, and data. Data governance, business data and business process standardization are all IT needs to be standardized. According to Liu Yi, author of "Private Domain Traffic Pool," the change of automotive digital marketing necessitates higher-level driving forces, such as leadership, corporate procedures, and methods of thinking[7]. The goal is to gain more users and more accurate users, as well as labeled and structured user data and user resources that can increase sales conversion rates.

During the epidemic, the vehicle manufacturing business relied on large-scale data for sales, production, and operations [2]. The previous method was simply offline experience, but the current method is a joint decision between experience and technology. Through the current method, user portraits and user identities have become specific, and users can also be accurately pushed. The sales department' $\mathrm{s}$ activities increased and the conversion rate increased, and the department finally achieved its sales target. BMW China, for example, has collaborated on the development of the "BMW Remote Digital Marketing Assistant," which provides dealers with multi-dimensional data labels and customer pictures[3]. The information is sent to the back-end management system, allowing front-line sales and management personnel to better understand the attributes, behavioral preferences, needs, channel sources and purchase intentions of consumers.

BMW China provides dealers with multi-dimensional marketing data, such as the number of views, views, and attention of each marketing material. In terms of user data, the number of user readings, the number of views of shared content, the number of views and duration, the number of comments, and the number of customers are all collected. Improve sales judgment and control over 
customers in this way BMW is currently promoting the "BMW Remote Digital Marketing Assistant" to more than 400 dealers across the country to provide more support to dealer partners. BMW has promoted the transformation of dealer service concepts and business methods, and provided customers with more personalized and convenient services[3].

\section{CONCLUSION}

In conclusion, the digital marketing revolution of auto firms will increase as consumer habits change and inconvenient situations arise as a result of the epidemic. However, digital marketing transformation will not happen immediately for many businesses. This is a long-term process, and the benefits of digital marketing transformation can only be seen in the long-term. Many institutions have reduced their global sales statistics as a result of the outbreak. The next two years will be the most difficult in the history of automobile companies. It is difficult to increase sales. This year's major goal will be survival. Manufacturers will more likely to follow the trends mentioned above to gain more clients. This study lacks surveys and interviews of people in the automotive industry. In the next research, these data can be further collected and analyzed

\section{ACKNOWLEDGMENT}

This thesis was completed under the guidance of Professor Capon. The professor's profound professional knowledge, serious scientific attitude has had a profound impact on me. It made me establish ambitious academic goals. I would like to extend my sincerest and heartfelt thanks to Professor Capon. In addition, the successful completion of this paper is inseparable from the care and help of the teachers. I would also like to thank Teacher Jane for their guidance and help. They have done a lot of work on this topic and helped me overcome difficulties one by one. Thank them very much.

\section{REFERENCES}

[1] S.Dolanay, Rapid Rise of China Automotive Industry in the 2000s and History of Turkey Automotive Industry. China-USA Business Review, 2021, 20(1).

[2] J. Haria, Organizational Change and Development during the COVID-19 Pandemic in Automotive Industry. SSRN Electronic Journal, 2021.

[3] M. Helmold, New Work in the Automotive Industry. Management for Professionals, 2021, 157-169.
[4] F. Hoeft, The case of sales in the automotive industry during the COVID-19 pandemic. Strategic Change, 30(2), 2021, 117-125.

[5] M. Krawina and A. Tschiesner, Reimagining the auto industry's future: It's now or never. McKinsey \& Company, 2020. Retrieved on June 29, 2021 https://www.mckinsey.com/industries/automotiveand-assembly/our-insights/reimagining-the-auto-in dustrys-future-its-now-or-never.

[6] N. Kaitwade, COVID-19 shatters global automotive industry; sales of metal powder take a nosedive amid wavering demand. Metal Powder Report, 76(3), 2021, 137-139.

[7] I. Kufelova and M. Rakova, Impact of the Covid-19 pandemic on the automotive industry in Slovakia and selected countries. SHS Web of Conferences, 83, 2020.

[8] G. Nhamo, K. Dube and D. Chikodzi, Impact of COVID-19 on Global Car Rental Industry and Ride and Share Transport Services. Counting the Cost of COVID-19 on the Global Tourism Industry, 2020, 159-181.

[9] I. Pisz,Impact Covid-19 pandemic on implementation Industry 4.0 in enterprises and supply chains. Scientific Papers of Silesian University of Technology. Organization and Management Series, 2021(150), 183-198. 